\title{
Predicting health-related quality of life in Spanish adolescents with allergic rhinoconjunctivitis and bronchial asthma
}

Laura Lacomba-Trejo, Selene Valero-Moreno, Inmaculada Montoya-Castilla \& Marian Pérez Marín

To cite this article: Laura Lacomba-Trejo, Selene Valero-Moreno, Inmaculada Montoya-Castilla \& Marian Pérez Marín (2021): Predicting health-related quality of life in Spanish adolescents with allergic rhinoconjunctivitis and bronchial asthma, Psychology, Health \& Medicine, DOI: 10.1080/13548506.2021.1904514

To link to this article: https://doi.org/10.1080/13548506.2021.1904514

曲 Published online: 24 Mar 2021.

Submit your article to this journal ๘

View related articles

View Crossmark data \lceil 


\title{
Predicting health-related quality of life in Spanish adolescents with allergic rhinoconjunctivitis and bronchial asthma
}

\author{
Laura Lacomba-Trejo (D), Selene Valero-Moreno (D), Inmaculada Montoya-Castilla \\ and Marian Pérez Marín (iD
}

Department of Personality, Assessment and Psychological Treatments, University of Valencia, Valencia, Spain

\begin{abstract}
This study analyzed the predictive power of sociodemographic (age, sex) and medical variables (months since diagnosis and in treatment, immunotherapy, number of environmental allergens, food allergies or atopic dermatitistypes) on the quality of life of patients with rhinoconjunctivitis and bronchial asthma, using models based on comparative qualitative fuzzy analysis to compare them according to the pathology(s).

Retrospective cross-sectional design.Sixty-four adolescents (65.60\% boys) diagnosed with rhinoconjunctivitis and/or bronchial asthma aged between 12 and 16 years old $(M=14.02 ; S D=1.45)$.

The data were collected between February 2019 and January 2020 using the Brief Disease Perception Questionnaire (B-IPQ), the Adolescent Rhinoconjunctivitis Quality of Life Questionnaire (AdolRQoLQ) and the Respiratory Disease Questionnaire Self-administered and Standardized Chronicle (CRQSAS). Qualitative comparative analysis models (QCA) were used.

In the QCA models, the various combinations indicated that the variables that predicted a higher quality of life for both rhinocojuntivitis symptoms and respiratory symptoms were receiving longerterm immunotherapy and a perceived lower threat of the disease. The consistencies of the models vary between $23-29 \%$. In conclusion, the patients' QoL was explained by the presence of longerterm immunotherapy and a less threatening perception of the disease.

Therefore, early multidisciplinary diagnosis and treatment is important.
\end{abstract}

\section{ARTICLE HISTORY}

Received 6 July 2020

Accepted 9 March 2021

\section{KEYWORDS}

Quality of life; allergic disease; adolescence; bronchial asthma; Rhinoconjunctivitis

\section{Introduction}

Allergic diseases are among the most common chronic diseases during childhood and adolescence, and have increased considerably in recent years (Cibella et al., 2015). The prevalence of allergic diseases varies depending on the diagnostic criteria considered, the age of the samples studied and the place of origin (Rodríguez Rodríguez et al., 2017). Around $7-20 \%$ of children and adolescents suffer from allergic diseases, with the 
presence of allergic rhinoconjunctivitis (ARC) and atopic dermatitis being very frequent, and to a lesser extent, allergic asthma and food allergy (Ojeda et al., 2018; Tang \& Mullins, 2017; Trisan-Alonso et al., 2014). The prevalence of asthma was $2 \%$ in Indonesia, it was 32\% in the United Kingdom and between 5.50\% - 15.40\% in Spain (Rodríguez Rodríguez et al., 2017). There is considerable variability in the prevalence and incidence of the disease between different ethnicities. Although the causes of these differences are unclear, they may be due to the influence of genetic and environmental factors, and differences in the diagnosis, treatment, and prevention of the disease (Umławska et al., 2013).

There is a high degree of comorbidity between different allergic diseases, and as such $\mathrm{ARC}$ is considered a risk factor for the development of asthma (Stern et al., 2019). Indeed, ARC and asthma can be considered manifestations of the same disease in two parts of the respiratory tract (Togias et al., 2019). In addition, 25\% of adolescents with asthma have food allergy, and most of them also have atopic dermatitis (Gore et al., 2016; Stern et al., 2019).

The therapeutic strategy for allergic diseases includes patient education, avoidance of allergens and contaminants, allergen-specific pharmacotherapy and immunotherapy (Lang \& Portnoy, 2017; Ray et al., 2016). Many pediatric patients receive immunotherapy (Frew, 2010), since although it generally consists of a monthly injection for 3 to 5 years, the effects persist and include the prevention of new allergies (Wise et al., 2018). Although the medication received varies greatly depending on the number of allergens, the type of expression of the allergy and its severity (GEMA, 2018), the barriers to compliance are similar. The main barriers are the unadjusted perception of the disease, as well as the perception of peers and family about the disease (De Benedictis \& Bush, 2017).

Suffering from an allergy has a significant impact on adolescents' quality of life (QoL), rest, activities of daily living and even academic performance (Blaiss et al., 2018; Devillier et al., 2016; Robinson et al., 2017). The concomitant presence of asthma implies poorer control and response to medical treatment for adolescents with ARC, which is accompanied by a greater severity and duration of the disease, and therefore a greater impact on the QoL (Mariño-Sánchez et al., 2018),

The adolescents' beliefs about the disease, its degree of control, severity and chronicity, are associated with the psychological health of patients with allergic diseases (Fellows et al., 2020), and these can influence their QoL (Colombo et al., 2019; James \& Caballero, 2020) and their emotional well-being (Confino-Cohen et al., 1999). Adolescents with allergic pathologies perceive their diseases as being not very understandable but long-lasting, and conclude that the potential threat to their health is moderate (Colombo et al., 2019; James \& Caballero, 2020), despite having successfully completed immunotherapy treatment (Confino-Cohen et al., 1999). As for sociodemographic variables, the literature has highlighted how adolescent girls tend to perceive their disease as more threatening than adolescent boys with more symptoms, and therefore present a more marked deterioration of their QoL (Colombo et al., 2019; James \& Caballero, 2020).

While various studies have analyzed the importance of each variable separately, there are few studies in the field of health psychology and medicine that have addressed them in overall terms following linear methodologies (Castellano et al., 2019; Valero-Moreno, 
et al., 2020; Villanueva et al., 2019). On that basis, the present study uses Qualitative Comparative Analyses (QCA) The objective was to analyze the effect of sociodemographic variables and medical variables (presence of food allergy or atopic dermatitis, immunotherapy treatment, immunotherapy time and number of allergens) and the threat of disease on the QoL of patients with ARC and asthma using QCA. The hypotheses were: (H1) In comparison to boys, girls with more symptoms will present a lower QoL; (H2) Adolescents who received immunotherapy for a longer period presented a better QoL in comparison to adolescents receiving immunotherapy for a shorter period; (H3) Threat perception is negatively related to QoL; (H4): Comorbidity of pathologies (atopic dermatitis, food allergy or higher number of allergens) is negatively related to QoL.

\section{Method}

\section{Procedures}

This was an observational and cross-sectional study. The data was collected between February 2019 and January 2020, at the Valencia General Hospital Consortium. Adolescent patients with allergic asthma were eligible to participate if they had received a diagnosis of rhinitis or ARC at least 6 months previously, they were 12-16 years old, and regularly attended the Hospital's Pediatric Allergology. Patients were excluded if they had any neurological problems, oncological disease or psychological diagnosis prior to the diagnosis.

The data was collected by members of the research team. Informed consent was requested from legal guardians, who were informed of the characteristics of the study, assured of the commitment to confidentiality, and about the recording of personal data. The permission of the Ethics Committees of the Valencia General Hospital Consortium and the reference hospital was obtained (H1435211034634).

\section{Participants}

The sample consisted of 64 Spanish adolescents (65.60\% boys) aged 12-16 years $(M=14.02 ; S D=1.45)$. All the adolescents had been diagnosed with asthma and rhinitis or rhinocojuntivitis.

\section{Data collection}

The variables analyzed were as follows:

\section{Sociodemographic and medical variables}

An ad hoc questionnaire was developed with questions concerning the following information: age, sex, months since diagnosis and in treatment, immunotherapy received if any and time receiving immunotherapy, number of environmental allergens, and comorbidity with food allergy or atopic dermatitis. 


\section{Psychological variables}

The Brief Disease Perception Questionnaire (B-IPQ): this is a measure of patients' cognitive and emotional representations of their disease (Broadbent et al., 2006; PachecoHuergo et al., 2012). This study used a new version, adapted and validated for patients with chronic pediatric disease by Valero-Moreno et al. (2020). The scale consists of 5 items, which are graded from 0 to 10 , in which the higher the total score, the greater the perception of the disease as a threat. The scale has demonstrated adequate psychometric properties Valero-Moreno, Castillo-Corullón et al. (2020) and has a reliability of .77 in this study.

The Health-related quality of life was assessed using specific questionnaires for allergic rhinoconjunctivis (AdolRQOLQ) and respiratory symptoms associated with bronchial asthma (CRQ-SAS).

The Adolescent Rhinoconjunctivitis Quality of Life Questionnaire (AdolRQOLQ): AdolRQOLQ is a quality of life assessment instrument for use specifically for the pediatric population with ARC (Juniper et al., 1994). It measures the impact, frequency and severity of allergic symptoms on the daily functioning of patients (De Graaf-in $\mathrm{T}$ Veld et al., 1996). It is composed of 25 direct items with 7 levels (ranging from $0=$ 'didn't bother me at all' to ' $6=$ bothered me a lot'). A higher score is indicative of a poorer QoL (Malizia et al., 2018). AdolRQOLQ has been shown to be a valid instrument (Juniper et al., 2007), and shows a reliability of .96 in this study.

The Respiratory Disease Questionnaire Self-administered and Standardized Chronicle (CRQ-SAS) (Vigil et al., 2011) adapted to the paediatric population with respiratory symptoms (Valero-Moreno et al., 2019). This consists of a total of 20 items grouped into four dimensions (dyspnea, fatigue, emotional function and disease control). The answers range from 1 to 7, with 1 being the most severe impact on QoL. Previous studies indicate adequate psychometric properties (Al Moamary \& Tamim, 2011; Valero-moreno et al., 2019; Vigil et al., 2011). It presented a reliability of .89 in our study.

\section{Data analysis}

Mean and standard deviations were calculated for the variables analyzed, and recoding took place according to cut-off points, and t-tests were performed to analyze the mean differences between groups using the SPSS statistical software package. The raw data from the participants' responses had to be transformed for the QCA. QCA models are based on a Boolean or intersection logic and assume the influence of an attribute or attributes on a specific outcome (equifinality). First, as suggested in the literature (Ragin, 2008), all the missing data were eliminated and all the conditions (variables) were calculated by multiplying the scores for their items. The values had to be recalibrated between 0 and 1 before the analysis was performed. When considering only two values, we used 0 (does not have the characteristic) and 1 (has the characteristic). With continuous variables or with factors from a survey, it was necessary to consider the following three thresholds: $10 \%$ (low-level or totally outside the set), $50 \%$ (intermediate level, neither inside nor outside the set), and 90\% (high level or totally inside the set). These three values had to be entered in order to perform an automatic re-calibration of values between 0 and 1 . In this case, the fsQCA software re-calibrated the values for psychological variables considering the three thresholds (Woodside, 
2013). The analysis establishes the necessary causes, which must always be present for a given result to occur. In addition, the sufficient conditions, which, although they do not always have to be present for a result to occur, can give rise to a specific result. QCA models enable the identification of the percentage of variance explained, or the cases in which the model is fulfilled, i.e. the coverage, and the indicators of goodness of fit, i.e. the consistency (Eng \& Woodside, 2012; Ragin, 2008). A condition is considered necessary when its consistency is $\geq .90$ (Ragin, 2008) and for sufficiency, a model is informative when the consistency is around or above .74 (Eng \& Woodside, 2012). QCA was carried out using the fsQCA software version 2.5 (Claude \& Christopher, 2014).

\section{Results}

\section{Medical variables}

The number of years since diagnosis ( $\mathrm{M}=77.48$ months; $\mathrm{SD}=52.38$ months $)$ and treatment $(\mathrm{M}=53.98$ months; $\mathrm{SD}=47.64$ months $)$ were similar. A majority of participants $(73.3 \%)$ were currently receiving immunotherapy. The average duration of immunotherapy at the time of the assessment was approximately two and a half years $(\mathrm{M}=32.61$; $\mathrm{SD}=27.98)$, ranging from 0 (never received immunotherapy or receiving their first dose) to 168 doses of immunotherapy. In addition to ACR and asthma, $20.3 \%$ presented a food allergy, and $31.3 \%$ of the total also presented atopic dermatitis.

\section{Psychological variables}

\section{Quality of life (CRQ-SAS vs AdolRQRQ)}

The results for QoL in allergic asthma patients were that patients generally presented an adequate QoL in both respiratory symptoms and rhinoconjunctivitis. The results for the ADOLrQoLQ were low scores, indicating a good QoL (measured as lower scores, better QoL). The subscales with the highest scores were for symptoms of rhinitis and practical problems (difficulty concentrating, doing schoolwork, difficulty sleeping, etc.) see (Figure 1). Meanwhile, in the CRQ-SAS questionnaire (respiratory symptoms), higher scores indicated a better QoL. The results show high scores (Figure 2). The scales that obtained the lowest scores were fatigue and emotional function.

\section{Qualitative comparative analysis of diffuse sets (QCA)}

First, in accordance with the literature, necessary analyses were performed (Table 1), followed by sufficiency analyses (Table 2). QoL in rhinocojuntivitis and in respiratory symptoms were established as the criterion variables (outcome condition), and sex, immunotherapy, duration of immunotherapy, number of allergens, the presence of food allergy and atopic dermatitis and the perceived threat of disease were established as predictor variables (causal conditions). 
6

5

4

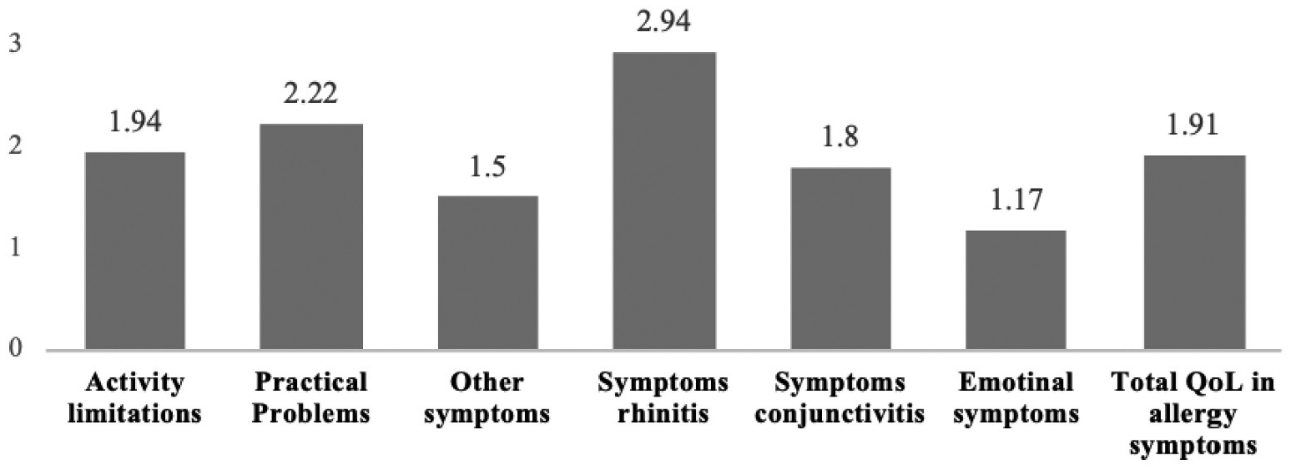

Figure 1. Average scores from the AdolqrQRQ questionnaire and its sub-dimensions.

7

\subsection{4}

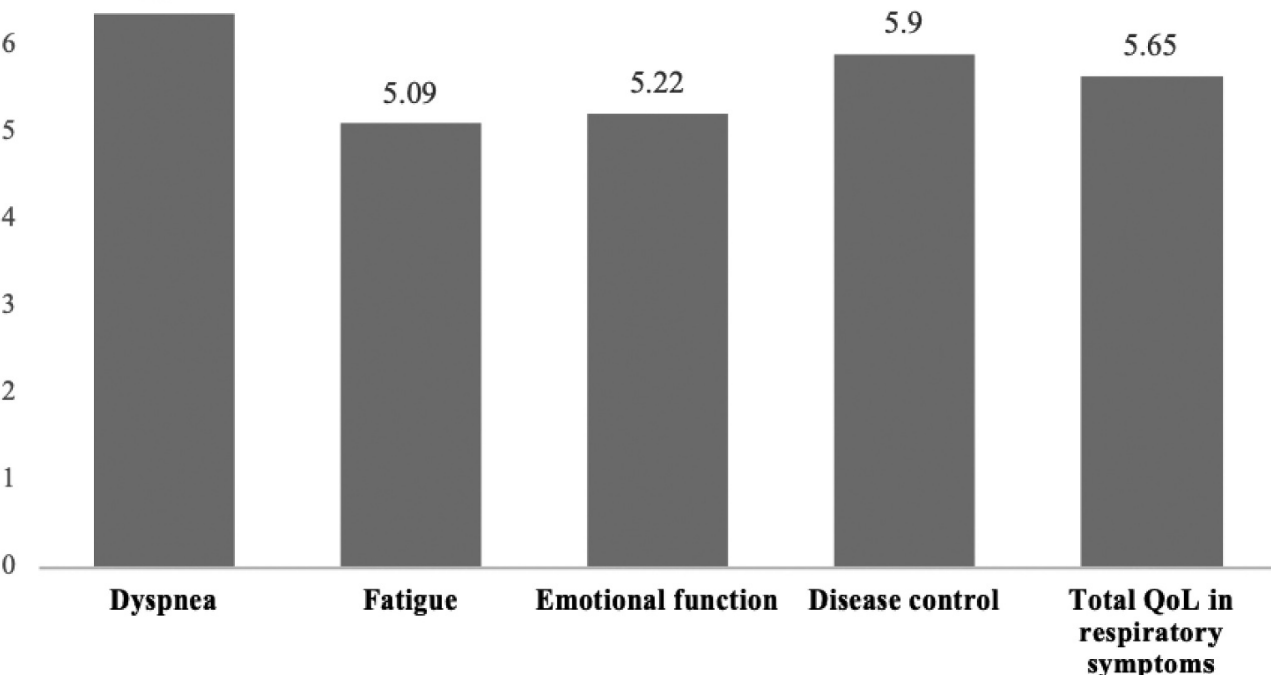

Figure 2. Average scores from the CRQ-SAS questionnaire and its sub-dimensions.

\section{Necessity analysis}

There is no necessary condition for high and low levels of QoL in rhinoconjunctivitis and in respiratory symptoms (Table 2), because its consistency was lower than 90. 
Table 1. Main descriptions and calibration values.

\begin{tabular}{lccccc}
\hline & $\begin{array}{c}\text { Immunotherapy } \\
\text { duration }\end{array}$ & $\begin{array}{c}\text { Number of environ- } \\
\text { mental allergens }\end{array}$ & $\begin{array}{c}\text { Threat of } \\
\text { disease }\end{array}$ & $\begin{array}{c}\text { Quality of life respira- } \\
\text { tory symptoms }\end{array}$ & $\begin{array}{c}\text { Quality of life rhinoconjunc- } \\
\text { tivitis symptoms }\end{array}$ \\
\hline M & 32.10 & 2.72 & 5918.23 & 318308.92 & 89833.71 \\
SD & 28.05 & 1.80 & 11482.70 & 165206.85 & 127355.31 \\
Min & 0 & 1 & 4 & 21420 & 1664 \\
Max & 120 & 8 & 57600 & 675024 & 566082 \\
P10 & 0 & 1 & 20 & 106343 & 3909.30 \\
P50 & 24 & 2 & 813 & 321048 & 30450 \\
P90 & 60 & 5 & 18477 & 544887 & 294692.40 \\
\hline
\end{tabular}

Note. M: mean; SD: standard deviation; Min: minimum; Max: maximum; P10: 10th percentile; P50: 50th percentile; P90: 90th percentile

Table 2. Necessary analysis for health-related quality of life (ADOLrQoLQ and CRQ-SAS).

\begin{tabular}{|c|c|c|c|c|c|c|c|c|}
\hline & \multicolumn{4}{|c|}{ AdolrQoLQ } & \multicolumn{4}{|c|}{ CRQ-SAS } \\
\hline & \multicolumn{2}{|c|}{$\begin{array}{l}\text { High levels of } \\
\text { ADOLrQoLQ (worse } \\
\text { quality of life in } \\
\text { rhinoconjunctivitis) }\end{array}$} & \multicolumn{2}{|c|}{$\begin{array}{l}\text { Low levels of } \\
\text { ADOLrQoLQ (better } \\
\text { quality of life in } \\
\text { rhinoconjunctivitis) }\end{array}$} & \multicolumn{2}{|c|}{$\begin{array}{l}\text { High levels of } \\
\text { quality of life } \\
\text { in respiratory } \\
\text { symptoms }\end{array}$} & \multicolumn{2}{|c|}{$\begin{array}{l}\text { Low levels of } \\
\text { quality of life } \\
\text { in respiratory } \\
\text { symptoms }\end{array}$} \\
\hline & Cons & Cov & Cons & Cov & Cons & Cov & Cons & Cov \\
\hline Girl & .41 & .59 & .23 & .41 & .24 & .33 & .42 & .67 \\
\hline Boy & .59 & .39 & .76 & .61 & .76 & .54 & .58 & .46 \\
\hline Immunotherapy & .30 & .59 & .17 & .41 & .20 & .39 & .28 & .61 \\
\hline No immunotherapy & .70 & .41 & .83 & .59 & .80 & .50 & .72 & .50 \\
\hline Increased immunotherapy duration & .59 & .52 & .63 & .67 & .72 & .64 & .52 & .51 \\
\hline Shorter immunotherapy duration & .62 & .59 & .54 & .61 & .46 & .46 & .64 & .72 \\
\hline Many allergens & .62 & .57 & .56 & .62 & .59 & .55 & .60 & .63 \\
\hline Few allergens & .59 & .53 & .61 & .66 & .61 & .58 & .57 & .61 \\
\hline Food allergy & .81 & .45 & .82 & .55 & .82 & .48 & .77 & .52 \\
\hline No food allergy & .19 & .47 & .18 & .53 & .18 & .42 & .23 & .58 \\
\hline Atopic dermatitis & .66 & .42 & .73 & .57 & .73 & .50 & .64 & .50 \\
\hline No atopic dermatitis & .34 & .51 & .27 & .49 & .27 & .40 & .36 & .60 \\
\hline High levels of disease threat & .71 & .80 & .39 & .53 & .39 & .43 & 67 & .83 \\
\hline Low levels of disease threat & .58 & .44 & .85 & .78 & .84 & .70 & .53 & .50 \\
\hline
\end{tabular}

Note: AdolrQoLQ: quality of life in rhinoconjunctivitis; CRQ-SAS: quality of life in bronchial asthma; Cons: consistency; Cov coverage; : absence of condition; condition needed: consistency $\geq .90$

\section{Sufficiency analysis}

The resulting models for each dimension provided the following results: in predicting high levels of QoL in rhinoconjunctivitis (measured in reverse, with higher scores denoting a poorer QoL), eight pathways were observed that explained $50 \%$ of the cases with high levels (total consistency $=.96$; total coverage $=.50$ ). The most relevant pathways for predicting high levels of QoL in rhinoconjunctivitis were the result of the interaction between high levels of disease threat, having a food allergy, receiving immunotherapy and shorter immunotherapy duration (raw coverage $=.15$, consistency $=.91$ ) (Table 3). Meanwhile, for predicting low levels QoL in rhinoconjunctivitis, six pathways were observed that explained $53 \%$ of the cases with low levels (total consistency $=.91$; total coverage $=.53$ ). The most relevant combinations were the result of few allergens, a shorter immunotherapy duration, no immunotherapy and being a boy (raw coverage $=.23$, consistency $=.93$ ), which explained $23 \%$ of the cases with low levels. 
Table 3. Summary of the three main conditions sufficient for the intermediate solution of Healthrelated quality of life.

\begin{tabular}{|c|c|c|c|c|c|c|c|c|c|c|c|c|}
\hline \multirow[b]{2}{*}{ Frequency cut-off 1} & \multicolumn{6}{|c|}{ AdolrQoLQ } & \multicolumn{6}{|c|}{ CRQ-SAS } \\
\hline & \multicolumn{3}{|c|}{$\begin{array}{c}\text { High levels of } \\
\text { ADOLrQoLQ (worse } \\
\text { quality of life in rhino- } \\
\text { conjunctivitis) } \\
\text { Consistency cut-off } .87\end{array}$} & \multicolumn{3}{|c|}{$\begin{array}{l}\text { Low levels of } \\
\text { ADOLrQoLQ (better } \\
\text { quality of life in rhino- } \\
\text { conjunctivitis) } \\
\text { Consistency cut-off . } 88\end{array}$} & \multicolumn{3}{|c|}{$\begin{array}{l}\text { High levels of } \\
\text { quality of life in } \\
\text { respiratory } \\
\text { symptoms } \\
\text { Consistency cut- } \\
\text { off .90 }\end{array}$} & \multicolumn{3}{|c|}{$\begin{array}{l}\text { Low levels of } \\
\text { quality of life in } \\
\text { respiratory } \\
\text { symptoms } \\
\text { Consistency cut- } \\
\text { off } .93\end{array}$} \\
\hline Girl & 1 & 2 & 3 & $\begin{array}{l}1 \\
\bigcirc\end{array}$ & $\begin{array}{l}2 \\
0\end{array}$ & $\begin{array}{l}3 \\
\bigcirc\end{array}$ & $\begin{array}{l}1 \\
0\end{array}$ & $\begin{array}{l}2 \\
0\end{array}$ & $\begin{array}{l}3 \\
\bigcirc\end{array}$ & 1 & 2 & 3 \\
\hline Immunotherapy & 0 & & & $\bigcirc$ & & O & & & & & $\bigcirc$ & \\
\hline $\begin{array}{l}\text { Immunotherapy duration } \\
\text { Number of allergens }\end{array}$ & $\bigcirc$ & $\bigcirc$ & & $\begin{array}{l}\bigcirc \\
\bigcirc\end{array}$ & & & & & & $\bigcirc$ & O & $\bigcirc$ \\
\hline Food allergy & 0 & 0 & 0 & & & 0 & & & & & 0 & $\bigcirc$ \\
\hline Atopic dermatitis & & & & & & & & $\bigcirc$ & & & $\bigcirc$ & 0 \\
\hline Levels of disease threat & 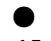 & O & 0 & & O & 0 & $\bigcirc$ & & $\bigcirc$ & O & O & 0 \\
\hline Raw coverage & .15 & .10 & .09 & .23 & .18 & .12 & .20 & .09 & .05 & .12 & .09 & .08 \\
\hline Unique coverage & .10 & .07 & .05 & .13 & .11 & .02 & .15 & .06 & .03 & .04 & .03 & .02 \\
\hline Consistency & .91 & 1 & .95 & .93 & .96 & .93 & .90 & .93 & .98 & .94 & .99 & .99 \\
\hline Overall solution consistency & & & .96 & & & .91 & & & .93 & & & .96 \\
\hline Overall solution coverage & & & .50 & & & .53 & & & .39 & & & .43 \\
\hline
\end{tabular}

Note: AdolrQoLQ: quality of life in rhinoconjunctivitis; CRQ-SAS: quality of life in bronchial asthma; Expected vector for high levels of quality of life in rhinoconjunctivitis: 1,0,0,1,1,1,1 (according to Fiss nomenclature) (Fiss,

2011)Expected vector for low levels of quality of life in rhinoconjunctivitis:0,1,1,0,0,0,0 $\bullet=$ presence of condition, o=absence of condition, $\sim=$ absence of condition. Expected vector for high levels of quality of life in respiratory symptomatology $0,1,1,0,0,0,0$. Expected vector for low levels of quality of life in respiratory symptomatology: $1,0,0,1,1,1,1$

In predicting high levels of QoL for respiratory symptoms, six pathways were observed that explained $39 \%$ of the cases with high levels (total consistency $=.93$; total coverage $=.39$ ). The most relevant pathways for predicting high levels of QoL for respiratory symptoms were the result of the interaction between low levels of disease threat, having atopic dermatitis, many allergens, increased immunotherapy duration and being a boy ( raw coverage $=.20$, consistency $=.90$ ). Meanwhile, for predicting low levels of QoL in respiratory symptoms, nine pathways were observed that explained $43 \%$ of the cases (total consistency $=.96$; total coverage $=.43$ ). The most relevant combinations were the result of high levels of disease threat, having atopic dermatitis, shorter immunotherapy duration and receiving immunotherapy (raw coverage $=.12$, consistency $=.94$ ), which explained $12 \%$ of the cases with low levels.

\section{Discussion}

Few studies focus on the QoL of adolescents with allergic diseases (Kansen et al., 2018; Muraro et al., 2014; Van Der Velde et al., 2011) and to the best of our knowledge, they have been carried out using linear methodologies. This study therefore proposed a methodology that provides different combinations of explanations for the same phenomenon. As regards the objective of our research, to find the explanatory factors of the affectation of QoL in adolescents with asthma and ARC, our results show that in general the presence of ARC and asthma may compromise the QoL of adolescents. It seems that the perception of the disease in adolescents must be very threatening and they must not be receiving any immunotherapy (or have received it for a very short time) for it to 
present any impact on their QoL. In our study, we found that most adolescents have a good QoL, which is accompanied by a low threat perception of allergic disease (James \& Caballero, 2020) this result would confirm H3.

As a result, adolescents who present a low QoL in terms of their respiratory symptoms have atopic dermatitis do not receive immunotherapy, and perceive the disease as very threatening, simultaneously validating $\mathrm{H} 2, \mathrm{H} 3$ and $\mathrm{H} 4$. In our results, we observed that a high QoL in terms of respiratory symptoms generally occurs in boys with a low perception of the threat of the disease, partially validating $\mathrm{H} 1$ and $\mathrm{H} 3$. This condition persists even in cases presenting food allergy and atopic dermatitis as indicated by the studies, and this confirms H4 (Colombo et al., 2019; James \& Caballero, 2020).

In addition, low QoL related to rhinoconjunctivitis symptoms was consistently associated with a greater perceived threat, food allergy, and no or recent immunotherapy treatment, therefore supporting $\mathrm{H} 2, \mathrm{H} 3$ and $\mathrm{H} 4$. The comorbid presence of several allergic diseases can seriously compromise the QoL of adolescents, with reports of increased perceived symptoms associated with nose and eye symptoms, validating $\mathrm{H} 4$.

A better QoL related to the symptomatology of rhinoconjunctivitis occurred in boys and was associated with fewer allergens and with the current absence of immunotherapy treatment. A good QoL in rhinoconjunctivitis is found in patients with the fewest environmental allergens as well as in adolescents with high levels of environmental allergens, food allergy, atopic dermatitis and a low perceived threat of disease.

As previous studies have suggested, adolescents' perception of the disease may define how they adjust to the disease (Valero-Moreno, Lacomba-Trejo et al., 2020). The results found using QCA models show that having more allergic diseases or more allergens does not necessarily lead adolescents to report greater impairment of their QoL. It is their interpretation of the disease and the presence of immunotherapy treatment that leads them to report fewer associated symptoms. However, although being a boy is generally associated with a more limited impact on QoL, the role of sex is not totally clear, and further studies are needed. It is important to analyze the role of psychosocial variables in pediatric allergic diseases due to the lack of studies on this topic (AUTHOR 1, Castillo-Corullón, et al., 2020).

Despite the contributions made by this study, its limited number of patients and monocentric nature may have altered its results, and as such research with a larger, nationwide population could obtain different results. Further studies are needed to replicate our research, using a probability sample that adequately represents the characteristics and peculiarities of Spanish adolescents with allergies. Future studies should have multiple informants and different methods of obtaining the information to assess the variables studied, which could reduce the errors commonly made in self-reports, and especially those related to social desirability. They could also consider the values obtained in spirometry, FeNO and IgE, and consider the nature of the allergens, since our results show that the presence of more inhalant allergens is not necessarily associated with a poorer QoL in adolescents with ARC and asthma.

The results obtained show that interventions that improve the perception of the disease in adolescents could be useful in improving their QoL. Similarly, longer treatment times with immunotherapy considerably improve the QoL of adolescents with ARC and asthma. These data should be considered when making medical decisions, as immunotherapy has 
been shown to be medically effective in about $80-90 \%$ of cases (Andreasen et al., 2020), but our study also sheds light on its impact on the emotional health of adolescents.

In conclusion, it is essential that health professionals specializing in caring for these patients have a thorough understanding of the psychological characteristics associated with allergic pathology, as this can help reduce the negative impact on their quality of life and improve their medical care.

\section{Disclosure statement}

The authors have no conflict of interest to declare.

\section{Funding}

This work was supported by the Generalitat Valenciana [ACIF2017/389]; Social European Found (ACIF) [ACIF2017/389]; Universitat de València [Atracció de Talent (0133/2018)].

\section{ORCID}

Laura Lacomba-Trejo (D) http://orcid.org/0000-0002-1990-9711

Selene Valero-Moreno (D) http://orcid.org/0000-0002-5228-2738

Inmaculada Montoya-Castilla (D) http://orcid.org/0000-0003-2536-2019

Marian Pérez Marín (D) http://orcid.org/0000-0003-3532-8818

\section{References}

Al Moamary, M. S., \& Tamim, H. M. (2011). The reliability of an arabic version of the self-administered standardized chronic respiratory disease questionnaire (CRQ-SAS). BMC Pulmonary Medicine, 11(1), 2-7. https://doi.org/10.1186/1471-2466-11-21

Andreasen, T. H., Christensen, M. O., Halling, A.-S., Egeberg, A., \& Thyssen, J. P. (2020). Placebo response in phase 2 and 3 trials of systemic and biological therapies for atopic dermatitis-a systematic review and meta-analysis. Journal of the European Academy of Dermatology and Venereology, 34(6), 1143-1150. https://doi.org/10.1111/jdv.16163

Blaiss, M. S., Hammerby, E., Robinson, S., Kennedy-Martin, T., \& Buchs, S. (2018). The burden of allergic rhinitis and allergic rhinoconjunctivitis on adolescents: A literature review. Annals of Allergy, Asthma \& Immunology: Official Publication of the American College of Allergy, Asthma, \& Immunology, 121(1), 43-52.e3. https://doi.org/10.1016/j.anai.2018.03.028

Broadbent, E., Petrie, K. J., Main, J., \& Weinman, J. (2006). The brief illness perception questionnaire. Journal of Psychosomatic Research, 60(6), 631-637. https://doi.org/10.1016/j. jpsychores.2005.10.020

Castellano Rioja, E., Giménez-Espert, M. D. C., \& Prado-Gascó, V., \& . (2019). The relations of quality of life in patients with lupus erythematosus: Regression models versus qualitative comparative analysis. Journal of Advanced Nursing, 75(7), 1484-1492. https://doi.org/10.1111/ jan.13957

Cibella, F., Ferrante, G., Cuttitta, G., Bucchieri, S., Melis, M. R., La Grutta, S., \& Viegi, G. (2015). The burden of rhinitis and rhinoconjunctivitis in adolescents. Allergy, Asthma \& Immunology Research, 7(1), 44-50. https://doi.org/10.4168/aair.2015.7.1.44

Claude, R., \& Christopher, R. (2014). Acq [Computer Programme] (Version 2.1.12.).

Colombo, D., Zagni, E., Ferri, F., \& Canonica, G. W. (2019). Gender differences in asthma perception and its impact on quality of life: A post hoc analysis of the PROXIMA (Patient Reported Outcomes and Xolair((R)) In the Management of Asthma) study. Allergy, Asthma, 
and Clinical Immunology : Official Journal of the Canadian Society of Allergy and Clinical Immunology, 15(1), 65. https://doi.org/10.1186/s13223-019-0380-z

Confino-Cohen, R., Melamed, S., \& Goldberg, A. (1999). Debilitating beliefs, emotional distress and quality of life in patients given immunotherapy for insect sting allergy. Clinical and Experimental Allergy: Journal of the British Society for Allergy and Clinical Immunology, 29 (12), 1626-1631. https://doi.org/10.1046/j.1365-2222.1999.00656.x

De Benedictis, D., \& Bush, A. (2017). Asthma in adolescence: Is there any news? Pediatric Pulmonology, 52(1), 129-138. https://doi.org/10.1002/ppul.23498

De Graaf-in T Veld, C., Garrelds, I. M., Koenders, S., \& Gerth Van Wijk, R. (1996). Relationship between nasal hyperreactivity, mediators and eosinophils in patients with perennial allergic rhinitis and controls. Clinical and Experimental Allergy: Journal of the British Society for Allergy and Clinical Immunology, 26(8), 903-908. https://doi.org/10.1046/j.1365-2222.1996.d01-395.x

Devillier, P., Bousquet, P.-J., Grassin-Delyle, S., Salvator, H., Demoly, P., Bousquet, J., \& De Beaumont, O. (2016). Comparison of outcome measures in allergic rhinitis in children, adolescents and adults. Pediatric Allergy and Immunology : Official Publication of the European Society of Pediatric Allergy and Immunology, 27(4), 375-381. https://doi.org/10. 1111/pai.12561

Eng, S., \& Woodside, A. G. (2012). Configural analysis of the drinking man: Fuzzy-set qualitative comparative analyses. Addictive Behaviors, 37(4), 541-543. https://doi.org/10.1016/j.addbeh. 2011.11.034

Fellows, J. L., Stimpson, A., Hussein, H., \& Mansur, A. H. (2020). Illness perceptions in difficult-totreat asthma compared with a depressed psychosis cohort. Annals of Allergy, Asthma \& Immunology, 124(2), 203-205. https://doi.org/10.1016/j.anai.2019.11.012

Fiss, P. C. (2011). Building better causal theories: A fuzzy set approach to typologies in organizational research. Academy of Management Journal, 54(2), 393-420. https://doi.org/10.5465/AMJ. 2011.60263120

Frew, A. J. (2010). Allergen immunotherapy. Journal of Allergy and Clinical Immunology, 125(2), S306-S313. https://doi.org/10.1016/j.jaci.2009.10.064

GEMA. (2018). Guía Española para el manejo del asma (GEMA 4.3).

Gore, C., Griffin, R., Rothenberg, T., Tallett, A., Hopwood, B., Sizmur, S., O’Keeffe, C., \& Warner, J. O. (2016). New patient-reported experience measure for children with allergic disease: Development, validation and results from integrated care. Archives of Disease in Childhood, 101(10), 935-943. https://doi.org/10.1136/archdischild-2015-309598

James, P., \& Caballero, M. R. (2020). Illness perception of adolescents with allergic conditions under specialist care. Pediatric Allergy and Immunology, 31(2), 197-202. https://doi.org/10. 1111/pai.13169

Juniper, E. F., Guyatt, G. H., Willan, A., \& Griffith, L. E. (1994). Determining a minimal important change in a disease-specific Quality of Life Questionnaire. Journal of Clinical Epidemiology, 47 (1), 81-87. https://doi.org/10.1016/0895-4356(94)90036-1

Juniper, E. F., Riis, B., \& Juniper, B. A. (2007). Development and validation of an electronic version of the Rhinoconjunctivitis quality of life questionnaire, European Journal of Allergy and Clinical Immunology,62(9), 1091-1093. https://doi.org/10.1111/j.1398-9995.2007.01370.x

Kansen, H. M., Le, T. M., Meijer, Y., Flokstra-de Blok, B. M. J., Welsing, P. M. J., Van Der Ent, C. K., Knulst, A. C., \& Van Erp, F. C. (2018). The impact of oral food challenges for food allergy on quality of life: A systematic review. Pediatric Allergy and Immunology, 29(5), 527-537. https://doi.org/10.1111/pai.12905

Lang, D. M., \& Portnoy, J. M. (2017). Allergy and immunology practice parameters and guidelines: The new normal. Annals of Allergy, Asthma \& Immunology, 119(6), 471-473. https://doi.org/10. 1016/j.anai.2017.08.008

Malizia, V., Fasola, S., Ferrante, G., Cilluffo, G., Gagliardo, R., Landi, M., Montalbano, L., Marchese, D., \& La Grutta, S. (2018). Comparative effect of beclomethasone dipropionate and cetirizine on acoustic rhinometry parameters in children with perennial allergic rhinitis: A randomized controlled trial. Journal of Investigational Allergology \& Clinical Immunology, 28(6), 392-400. https://doi.org/10.18176/jiaci.0263 
Mariño-Sánchez, F., Valls-Mateus, M., \& Mullol, J. (2018). Multimorbilidad en la rinitis alérgica pediátrica.Revista de rinología, 18(2), 54-64.https://revistaderinologia.com/files/2018_18_2_054064.pdf

Muraro, A., Dubois, A. E. J., DunnGalvin, A., Hourihane, J. O., De Jong, N. W., Meyer, R., Panesar, S. S., Roberts, G., Salvilla, S., Sheikh, A., Worth, A., \& Flokstra-de Blok, B. M. J. (2014). EAACI food allergy and anaphylaxis guidelines. Food allergy health-related quality of life measures. Allergy, 69(7), 845-853. https://doi.org/10.1111/all.12405

Ojeda, P., Ibáñez, M. D., Olaguibel, J. M., Sastre, J., \& Chivato, T. (2018). Alergologica 2015: A national survey on allergic diseases in the Spanish pediatric population. Journal of Investigational Allergology \& Clinical Immunology, 28(5), 321-329. https://doi.org/10.18176/ jiaci.0308

Pacheco-Huergo, V., Viladrich, C., Pujol-Ribera, E., Cabezas-Peña, C., Núñez, M., Roura-Olmeda, P., Amado-Guirado, E., Núñez, E., \& Del Val, J. L. (2012). Percepción en enfermedades crónicas: Validación lingüística del illness perception questionnaire revised y del brief illness perception questionnaire para la población española. Atencion Primaria, 44(5), 280-287. https://doi.org/10. 1016/j.aprim.2010.11.022

Ragin, C. C. (2008). Redesigning Social Inquiry: Fuzzy sets and beyond. University of Chicago Press.

Ray, A., Raundhal, M., Oriss, T. B., Ray, P., \& Wenzel, S. E. (2016). Current concepts of severe asthma. The Journal of Clinical Investigation, 126(7), 2394-2403. https://doi.org/10.1172/ JCI84144

Robinson, S., Buchs, S., Hammerby, E., \& Kennedy-Martin, T. (2017). A review of the quality of life and educational burden of allergic rhinitis on adolescents. Value in Health, 20(9), A648. https://doi.org/10.1016/j.jval.2017.08.1508

Rodríguez Rodríguez, M., Antolín Amérigo, D., Barbarroja Escudero, J., \& Sánchez González, M. J. (2017). Actualización en asma. Medicine - Programa De Formación Médica Continuada Acreditado, 12(30), 1745-1756. https://doi.org/10.1016/j.med.2017.03.010

Stern, J., Jusko, T. A., Fagnano, M., Thevenet-Morrison, K., \& Halterman, J. S. (2019). Prevalence of food allergy in at-risk asthmatic adolescents. Journal of Allergy and Clinical Immunology, 143 (2), AB108. https://doi.org/10.1016/j.jaci.2018.12.328

Tang, M., \& Mullins, R. (2017). Food allergy: Is prevalence increasing? Clinical Perspectives, 47(3), 256-261. https://doi.org/10.1111/imj.13245

Togias, A., Gergen, P. J., Hu, J. W., Babineau, D. C., Wood, R. A., Cohen, R. T., Makhija, M. M., Khurana Hershey, G. K., Kercsmar, C. M., Gruchalla, R. S., Liu, A. H., Wang, E., Kim, H., Lamm, C. I., Bacharier, L. B., Pillai, D., Sigelman, S. M., Gern, J. E., \& Busse, W. W. (2019). Rhinitis in children and adolescents with asthma: Ubiquitous, difficult to control, and associated with asthma outcomes. The Journal of Allergy and Clinical Immunology, 143(3), 1003-1011.e10. https://doi.org/10. 1016/j.jaci.2018.07.041

Trisan-Alonso, A., López-Viña, A., \& Ussetti-Gil, P. (2014). Actualización en asma. Actualización-Medicine, 11(6), 3861-3873. https://doi.org/10.1016/S0304-5412(14)70856-X.

Umławska, W., Gąszczyk, G., \& Sands, D. (2013). Physical development in children and adolescents with bronchial asthma. Respiratory Physiology \& Neurobiology, 187(1), 108-113. https:// doi.org/10.1016/j.resp.2013.02.012

Valero-Moreno, S., Castillo-Corullón, S., Montoya-Castilla, I., \& Pérez-Marín, M. (2020). Primary ciliary dyskinesia and psychological well-being in adolescence. Plos One, 15(1), e0227888. https://doi.org/10.1371/journal.pone.0227888

Valero-moreno, S., Castillo-Corullón, S., Prado-Gascó, V.-J., Pérez-Marín, M., \& MontoyaCastilla, I. (2019). Chronic respiratory disease questionnaire (CRQ-SAS): Analysis of psychometric properties. Archivos Argentinos de Pediatria, 117(3), 149-155. https://doi.org/10.5546/ aap.2019.eng.149

Valero-Moreno, S., Lacomba-Trejo, L., Casaña-Granell, S., Prado-Gascó, V. J., Montoya-Castilla, I., \& Pérez-Marín, M. (2020). Psychometric properties of the questionnaire on threat perception of chronic illnesses in pediatric patients. Revista Latino-Americana De Enfermagem, 28., e3242https://doi.org/10.1590/1518-8345.3144.3242 
Van Der Velde, J. L., Flokstra-de Blok, B. M. J., Hamp, A., Knibb, R. C., Duiverman, E. J., \& Dubois, A. E. J. (2011). Adolescent-parent disagreement on health-related quality of life of food-allergic adolescents: Who makes the difference? Allergy, 66(12), 1580-1589. https://doi. org/10.1111/j.1398-9995.2011.02726.x

Vigil, L., Güell, M. R., Morante, F., López De Santamaría, E., Sperati, F., Guyatt, G., \& Schünemann, H. (2011). Validez y sensibilidad al cambio de la versión española autoadministrada del cuestionario de la enfermedad respiratoria crónica (CRQ-SAS). Archivos de Bronconeumologia, 47(7), 343-349. https://doi.org/10.1016/j.arbres.2011.02. 016

Villanueva, L., Valero-Moreno, S., Cuervo, K., \& Prado-Gascó, V. J. (2019). Sociodemographic variables, risk factors, and protective factors contributing to youth recidivism. Psicothema, 31 (2), 128-133. https://doi.org/10.7334/psicothema2018.257

Wise, S. K., Lin, S. Y., Toskala, E., Orlandi, R. R., Akdis, C. A., Alt, J. A., Azar, A., Baroody, F. M., Bachert, C., \& Canonica, G. W. (2018). International consensus statement on allergy and rhinology: Allergic rhinitis. International Forum of Allergy \& Rhinology, 8(2), 108-352. https://doi.org/10.1002/alr.22073

Woodside, A. G. (2013). Moving beyond multiple regression analysis to algorithms: Calling for adoption of a paradigm shift from symmetric to asymmetric thinking in data analysis and crafting theory. Journal of Business Research, 66(4), 463-472. https://doi.org/10.1016/j.jbusres. 2012.12.021 